\title{
Reuse of Carbon Paste from Used Zinc-Carbon Battery for Biogas Desulfurizer with Clay as a Binder
}

\author{
Tjokorda Gde Tirta Nindhia, I. Wayan Surata, I. Dewa Gede Putra Swastika, and I. Made Wahyudi
}

\begin{abstract}
The batteries containing materials which are dangerous for health and safety of environment. In some type of battery, its application should be replaced when the power get lost. The waste of used battery should be well manage or even reused again for other useful purpose to reduce dangerous risk for heal and environment. The zinc-carbon battery is a type of battery that can be used only one time, consist of carbon rod as positive terminal, zinc case as negative terminal, and mixture of carbon powder, ammonium chloride, and $\mathrm{MnO}_{2}$ as electrolyte. Hydrogen sulfide $\left(\mathrm{H}_{2} \mathrm{~S}\right)$ is impurities found in the biogas and should be purified before further application as fuel for engine. Hydrogen Sulfide $\left(\mathrm{H}_{2} \mathrm{~S}\right)$ is rising problem for the engine since will caused acidity to lubricant and corrosive to metal part of the engine. In this research the carbon powder of electrolyte part of the used zinc-carbon battery is reused as desulfurizer. Clay is added as a binder to make possible to create a pellet. It is found that the carbon powder from used zinc carbon battery is excellent as desulfurizer by adding clay as binder
\end{abstract}

Index Terms-Battery, zinc-carbon, carbon paste, desulfurizer, biogas.

\section{INTRODUCTION}

The zinc-carbon battery is widely used due to low price and available everywhere. The zinc-carbon battery consist of zinc case as a container and negative terminal, carbon road as positive terminal and mixture of $\mathrm{MnO}_{2}$, graphite powder and ammonium chloride $\left(\mathrm{NH}_{4} \mathrm{Cl}\right)$ as electrolyte [1] as can be seen in Fig. 1. After used or spent, the used battery still contains ammonium chloride which is mildly acidic that can be disturb the balance of the nature if the used battery is discarded carelessly. Manganese dioxide $\left(\mathrm{MnO}_{2}\right)$ is known as hazards material that can stain the human skin.

The zinc-carbon battery is popular energy source for portable electrical energy. It is a challenge to achieve the recycling of consumer-type batteries. Individuals should cooperate in such a program in order to ensure its success. Basic on energy balance of the chemical active part of the battery, the value and supply of the material and finally the steps and alternative route to the recycling of zinc-carbon batteries, it is found that it is necessary and useful to recycle zinc batteries [2].

The recycle of certain part of the zinc-carbon battery for

Manuscript received January 31, 2015; revised June 1, 2015. This work was supported financially by the Ministry of Education Culture, The Republic of Indonesia through second phase scheme of competitive research grant (skim penelitianhibahbersaing) for the year of 2015 granted through UdayanaUniversity, Jimbaran, Bali, Indonesia.

The authors are with the Department of Mechanical Engineering, Engineering Faculty, Udayana University Jimbaran, Bali, Indonesia (e-mail: nindhia@yahoo.com). desulfurizer has been done intensively with remarkable result [1]. The zinc case of zinc-carbon battery is already successfully utilized as biogas desulfurizer by applying galvanic coupling method [1]. The zinc case was taken out and cut to become small pieces and iron chips is prepared for galvanic coupling. The composition was immersed in to the salt water solution in order corrosion to occur and resulting corrosion product that reactive to $\mathrm{H}_{2} \mathrm{~S}$.

Other part from waste of zinc-carbon battery that already investiged for biogas desulfurizer is the carbon rod [3]. The carbon rod from waste of zinc-carbon battery is potential to be recycled as desulfurizer of biogas. The carbonrod can be directly use as desulfurizer. The carbon rod can be processed by putting in the solution of $\mathrm{KMnO}_{4}$ with oncentration minimum 20 gram $\mathrm{KMnO}_{4}$ in 1 liter water to increase the performance of the desulfurizer. It is suggested to use low level of flow rate of the biogas (around 1-3 liters/minute) to achieve best performance of desulfurizerduring application to.

Adsorption is a surface based adhesion of molecules, atoms ions or dissolved solid to a surface and create process a film on the surface of the adsorbent. Adsorbents commercially are usually in the form of particulate (spherical, rods, moldings, or monoliths). It is designed having small pore diameters, to yield higher surface area for high surface capacity of adsorption. By using adsorption process, the $\mathrm{H}_{2} \mathrm{~S}$ contaminant in the biogas can be removed. Activated carbon [4] were recognized as successful desulfurizer for biogas. Beside as desulfurizer, Activated carbons are the adsorbents with the most favorable characteristics for natural gas storage, because have a large microporous volume, are efficiently compacted into a packed [4].

The manufacturing process consists of two steps which are carbonization and activation. The carbonization process includes drying and then heating to separate with tars and other hydrocarbons of any gases generated. The next step is carbonized particles by exposing them to an oxidizing agent such or usually steam at high temperature [5]. This agent eliminated pore blocking structures created during the carbonization phase and develop a porous structure. Carbon active such as made from bituminous was found success to be used as desulfurizer by using various chemical treatments, such as nitric acid (HNO) oxidation, metal ( $\mathrm{Zn}$ and $\mathrm{Cu}$ ) impregnation, and thermal desorption of oxygen functional groups [6].

Biogas is produced from anaerobic biodegradation of biomass in the absence of oxygen and the presence of anaerobic microorganisms. Biogas is source of renewable methane which is deriving from biomass sources and has great potential for growth to meet future energy demands [7]. 
Anaerobic digestion is a series of metabolic interactions of microorganisms. The process is carried out in digesters at temperatures ranging from 30 to $65^{\circ} \mathrm{C}$ [8]. Anaerobic digesters are designed to operate in the mesophilic $\left(20-40^{\circ} \mathrm{C}\right)$ or thermophilic (above $40^{\circ} \mathrm{C}$ ) temperature zones. Sludge produced from the anaerobic digestion is often used as a fertilizer. Biogas recovery technologies have been failures in many developing countries, with low rates of technology transfer and longevity and a reputation for being difficult to operate and maintain. Designs which deliver lower cost, improved robustness, functionality, ease of construction, operation and maintenance would aid the market penetration of biogas plan [8].

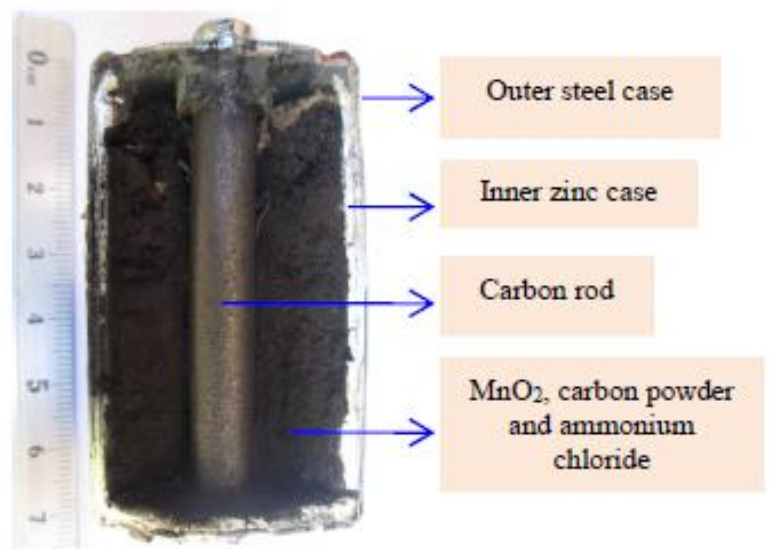

Fig. 1. Cross section of zinc-carbon battery.

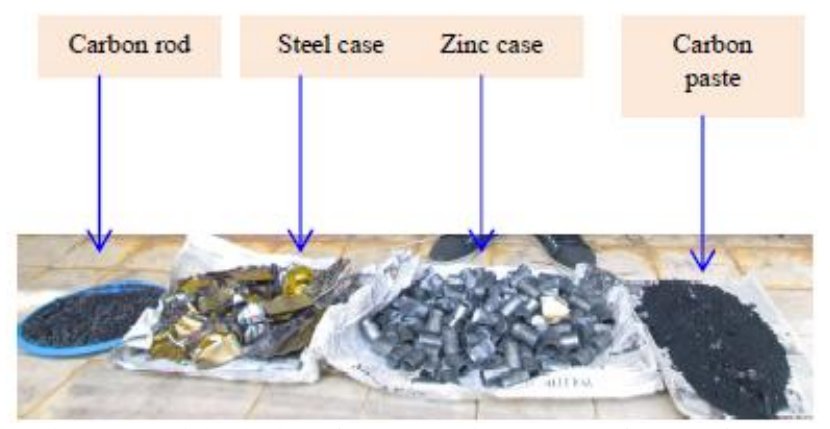

Fig. 2. Materials obtained from separation process of waste of used zinc-carbon battery.

There is greater potential for biogas as a transport vehicle fuel. For this purpose, biogas is be compressed in gas cylinders. This is possible only after removing hydrogen sulfide $\left(\mathrm{H}_{2} \mathrm{~S}\right)$ [7]. Hydrogen sulfide $\left(\mathrm{H}_{2} \mathrm{~S}\right)$ is contaminant in biogas and other $\mathrm{S}$-containing compounds that come from S-bearing organic matters which is depending on the composition of the organic matter. The $\mathrm{H}_{2} \mathrm{~S}$ content in biogas vary from 100 to $10.000 \mathrm{ppm}$. This contaminant is undesirable in combustion systems due to its conversion to highly corrosive and environmentally hazardous compounds. It is essential to remove before any further utilization of biogas [7]-[10].

Hydrogen sulfide is a pollutant that is regarded as toxic. Inhalation of high concentrations of hydrogen sulfide can be lethal. Hydrogen sulfide mainly attacks the neural system and important organs, like the liver and the kidney [11]. Together with $\mathrm{CH}_{4}$ in the biogas, $\mathrm{H}_{2} \mathrm{~S}$ burns in engines, and it exhausts in the form of $\mathrm{SO}_{2}$ which is more dangerous than $\mathrm{H}_{2} \mathrm{~S}$ as it is hazardous for health and environment such as smog and acid rain. Several small scale plants and projects using biogas have ended because of the corrosion problem of $\mathrm{H}_{2} \mathrm{~S}$. Owing to the potential problems that $\mathrm{H}_{2} \mathrm{~S}$ can cause, it is necessary to remove it prior to its use as stable product, at least as a solid residue that can be disposed off easily and safely [12].

Hydrogen sulfide can cause damage in piping and motors, it is typically removed in an early state of the biogas upgrading process. Several techniques are applied: 1) removal of $\mathrm{H}_{2} \mathrm{~S}$ during digestion and 2) removal of $\mathrm{H}_{2} \mathrm{~S}$ after digestion [13]. During digestion, removal of $\mathrm{H}_{2} \mathrm{~S}$ can be done by dosing air of oxygen in to digester of by adding iron chloride into the digester. Meanwhile $\mathrm{H}_{2} \mathrm{~S}$ can be removed after digestion by using several techniques such as adsorption, biological filter or membrane separation. Adsorption can be carried out by using Iron oxide, liquid, or activated carbon [13].

As presented in Fig. 2, the separation process of used zinccarbon battery yield 4 main items namely carbon rod, steel case, zinc case, and carbon paste. This work introduce successful work on the effort of reuse carbon paste from used zinc-carbon battery as desulfurizer for biogas purification. Clay is utilized in this research as a binder. The simultaneous solving problems of battery waste and harmful gas of $\mathrm{H}_{2} \mathrm{~S}$ in the biogas can be solved by technique that is explained in this article.

\section{EXPERIMENTAL}

The carbon paste from the used zinc-carbon battery was taken out from the body of the battery and mixed homogenously with clay. It was prepared four variation of compositions (mass fraction)) namely: $0 \%$ carbon $+100 \%$ clay, $25 \%$ carbon $+75 \%$ clay, $50 \%$ carbon $+50 \%$ clay, and $75 \%$ carbon $+25 \%$ clay. The mixtures are added with water and extruded, continued with drying. A cut of small rods from dry mixture was easy obtained (Fig. 3). About $100 \mathrm{~g}$ of mixture of each variation is taken as desulfurizer and installed as can be seen in Fig. 4.

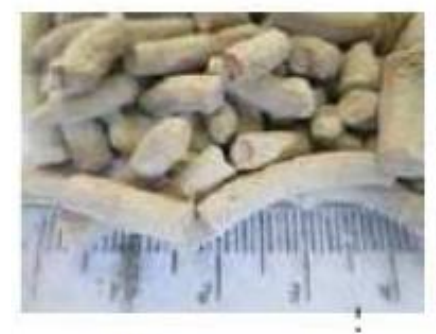

(a)

(c)

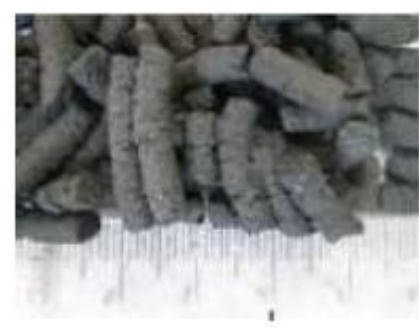

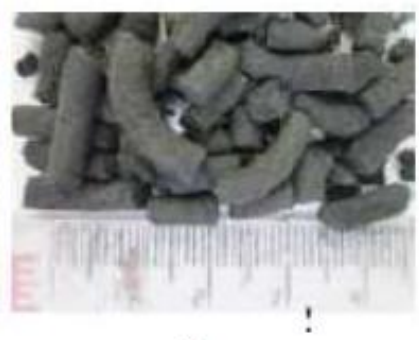

(b)

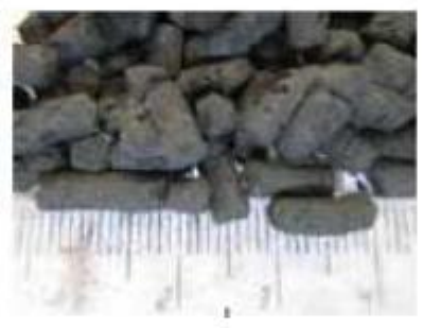

(d)
Fig. 3. Pellets obtained from mixing of carbon paste from used zinc-carbon battery mixed with clay. (a). $0 \%$ carbon $+100 \%$ clay, (b) $25 \%$ carbon $+75 \%$ clay, (c) $50 \%$ carbon $+50 \%$ clay, and (d) $75 \%$ carbon $+25 \%$ clay. 
The performance of each four variations of desulfurizers then was investigated by following schematic that is presented in Fig. 4. This schematic was from our previous publication [3].

The flow rate of biogas was arranged about 3 liters/minute. The performance of desulfurizer was evaluated by measuring the $\mathrm{H}_{2} \mathrm{~S}$ contents in the biogas before and after passing the desulfurizer as can be seen in Fig. 4. The biogas was let flow from gas container 1 with flow rate was controlled by using valve 2 . The flow rate was checked by using flow rate indicator 3 .

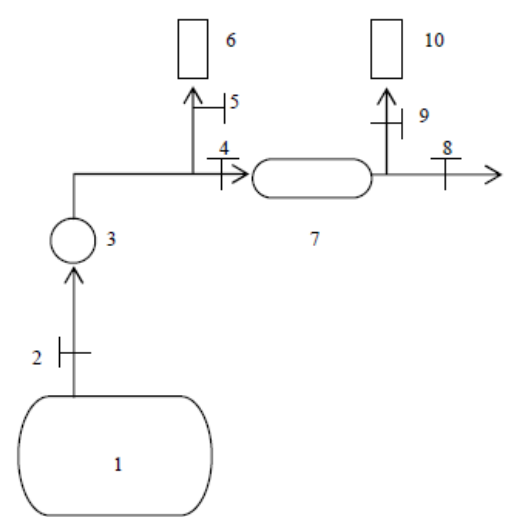

Fig. 4. Schematic of experiment for desulfurizer test performance: 1. Biogas container, 2.Valve, 3.Flow rate indicator, 4. Valve, 5. valve, $6 . \mathrm{H}_{2} \mathrm{~S}$ gas sensor, 7. Desulfurizer, 8. Valve, 9.valve, 10. $\mathrm{H}_{2} \mathrm{~S}$ gas sensor [3].

To measure the $\mathrm{H}_{2} \mathrm{~S}$ contents in the biogas before entering the desulfurizer, the valve 4 was closed and the valve 5 was opened and let the biogas flow to the $\mathrm{H}_{2} \mathrm{~S}$ gas sensor 6 . If the desulfurizer working well, then the $\mathrm{H}_{2} \mathrm{~S}$ contents in the biogas will decrease and can be measured by closing valve 8 and open the valve 9 and let the biogas flow to the $\mathrm{H}_{2} \mathrm{~S}$ gas sensor 10. The performance of desulfurizer then can be calculated by using Equation 1. The performance of desulfurizer was measured after passing 50 liters of biogas through desulfurizer.

\section{$\frac{\mathrm{H}_{2} \mathrm{~S} \text { before desulfurizer }-\mathrm{H}_{2} \mathrm{~S} \text { after desulfurizer }}{\mathrm{H}_{2} \mathrm{~S} \text { before desulfurizer }} \times 100$}

\section{RESULT AND DISCUSSION}

The result of investigation is presented in TABLE I. Clay is found possible to be used as desulfurizer but the performance is found not sufficient (the performance only 27.78\%) that can be seen in Fig. 5. Clay can act as desulfurizer due to chemisorption mechanism [14]. By addition just only $25 \%$ carbon paste, the performance of desulfurizer increase significantly and reach optimum performance. It can be understood that if activated carbon containing metal is added in to the clay, the performance as desulfurizer will be increase [15]. The carbon paste containing $\mathrm{MnO}_{2}$ in which the manganese is a metal that can increase the performance as desulfurizer.

TABLE I: HYDROGEN SULFIDE $\left(\mathrm{H}_{2} \mathrm{~S}\right)$ CONCENTRATION BEFORE AND AFTER DESULFURIZATION OF 50 LITER BIOGAS

\begin{tabular}{|c|cc|c|c|c|c|c|}
\hline \hline & \multicolumn{5}{c}{$\mathrm{H}_{2} \mathrm{~S}$ concentration before and after desulfurization of 50 liter biogas (ppm) } \\
\hline \multicolumn{2}{|c|}{$0 \% \mathrm{C}+100 \%$ clay } & \multicolumn{2}{c|}{$25 \% \mathrm{C}+75 \%$ clay } & \multicolumn{2}{c|}{$50 \% \mathrm{C}+50 \%$ clay } & after & before \\
\hline before & after & before & after & before & after \\
\hline 91.67 & 66.2 & 91.67 & 0 & 91.67 & 0 & 91.67 \\
\hline \hline
\end{tabular}

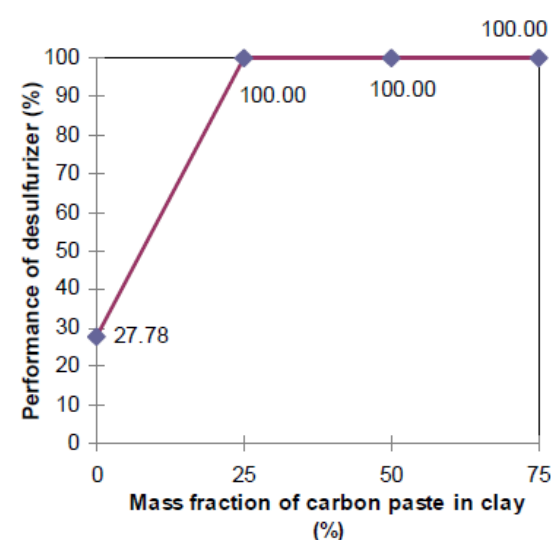

(\%)

Fig. 5. Effect of mass fraction of carbon paste in clay on performance of biogas desulfurizer

Addition of carbon paste in to the clay for mass fraction more than $25 \%$ until reach $74 \%$ are found not reduce the performance of desulfurizer. After passing of about 50 liter biogas, the performance of the desulfurizer still in optimum performance.

With the idea introduce in this article in which desulfurizer of biogas is made from reused carbon paste of waste zinc-carbon battery, two problem can solve simultaneously. The first problem is management of waste zinc-carbon battery can be solved and also the harmful gas of $\mathrm{H}_{2} \mathrm{~S}$ can be eliminated from the biogas.

\section{CONCLUSION}

The carbon paste from waste of zinc-carbon battery is potential to be reused as biogas desulfurizer by using clay as a binder. With addition of about $25 \%$ carbon paste in clay, the mixture can be used as a good desulfurizer in which best performance is achieved. Addition more that $25 \%$ until reach $75 \%$ carbon paste is found not reduce the performance of desulfurizer.

\section{ACKNOWLEDGMENT}

The authors wish to thanks the Ministry of National and Culture of The Republic of Indonesia for financial support under third phase scheme of competitive research grant (skim penelitianhibahbersaing) for the year of 2015 granted through UdayanaUniversity, Jimbaran, Bali, Indonesia

\section{REFERENCES}

[1] T. G. T. Nindhia, I. W. Surata, I. K. A. Atmika, D. N. K. P. Negara, and I. W. P. Adnyana, "To recycle zinc ( $\mathrm{Zn}$ ) from used zinc-carbon battery 
as biogas desulfurizer," International Journal of Materials Science and Engineering, vol. 2, no. 1, pp. 39-42, June 2014.

[2] J. P. Wiaux and J. P. Waefler, "Recycling zinc batteries: An economical challenge in consumer waste," Journal of Power Source, vol. 57, pp. 61-65, 1995.

[3] T. G. T. Nindhia, I. W. Surata, I. K. A. Atmika, D. N. K. P. Negara, and I. P. G. Artana, "Processing carbon rod from waste of zing-carbon battery for biogas desulfurizer," Journal of Clean Energy Technologies, vol. 3, no. 2, pp. 119-122, March 2015.

[4] I. A. A. C. Esteves, M. S. S. Lopes, P. M. C. Nunes, and J. P. B. Mota, "Adsorption of natural gas and biogas components on activated carbon," Separation and Purification Technology, vol. 62, pp. 281-296, January 2008.

[5] D. Mescia, S. P. Hernandes, A. Conoci, and N. Russo, "MSW landfill biogas desulfurization," International Journal of Hydrogen Energy, vol. 36, pp. 7884-7890, February 2011.

[6] M. P. Cal, B. W. Strickler, A. A. Lizzio, and S. K. Gangwal, "High temperature hydrogen sulfide adsorption on activated Carbon. II. Effects of gas temperature, gas pressure and sorbent regeneration," Carbon, vol. 38, pp. 1767-1774, 2000.

[7] N. Tippayawong and $\mathrm{P}$. Thanompongchart, "Biogas quality upgrade by simultaneous removal of $\mathrm{CO}_{2}$ and $\mathrm{H}_{2} \mathrm{~S}$ in a packed column reactor," Energy, vol. 35, pp. 4531-4535, May 2010.

[8] T. Bond and M. R. Templeton, "History and future of domestic biogas plants in the developing world," Energy for Sustainable Development, vol. 15 , pp. 347-354, 2011

[9] L. V. A. Truong and N. Abatzoglou, "A $\mathrm{H}_{2} \mathrm{~S}$ reactive adsorption process for the purification of biogas prior to its use as a bioenergy vector," Biomass and Bioenergy, vol. 29, pp. 142-151, 2005.

[10] A. B. Baspinar, M. Turker, A. Hocalar, and I. Ozturk, "Biogas desulphurization at technical scale by lithotrophicdenitrification: Integration of sulphide and nitrogen removal," Process Biochemistry, vol. 46, pp. 916-922, January, 2011.

[11] W. Feng, S. Kwon, E. Borguet, and R. Vidic, "Adsorption of hydrogen sulfide onto activated carbon fibers: Effect of pore structure and surface chemistry," Environ. Sci. Technol, vol. 39, pp. 9744-9749, November 2005.

[12] J. S. Lar and L. Xiujin, "Removal of $\mathrm{H}_{2} \mathrm{~S}$ during anaerobic ioconversion of dairy manure," Bioterchnology and Bioengineering, vol. 17, pp. 273-277, 2009.

[13] M. R. Drouillon and H. Vervaeren, "Techniques for transformation of biogas to biomethane," Biomass and Bioenergy, vol. 35 pp. 1633-1645, March 2011.

[14] R. K. Tabase, D. Liu, and A. Feilberg, "Chemisorption of hydrogen sulphide and methanethiol by light expanded clay aggregates (Leca)," Chemosphere, vol. 93, pp. 1345-1351, August 2014.

[15] D. Nguyen-Thanh and T. J. Bandosz, "Activated carbons with metal containing bentonite binders as adsorbents of hydrogen sulfide," Carbon, vol. 43, pp. 359-367, 2005.

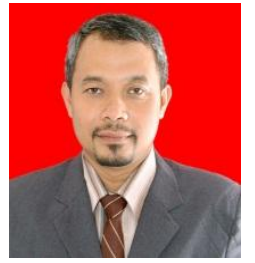

Tjokorda Gde Tirta Nindhia was born in Denpasar, Bali, Indonesia on January $16^{\text {th }}, 1972$. He received the doctor degree in mechanical engineering from Gadjah Mada University (UGM) Yogyakarta, Indonesia in August 2003, with major field of material engineering.

He participated in various international research collaboration such as with Muroran Institute of Technology Japan (2004), Toyohashi University of Technology Japan (2006), Leoben Mining University Austria (2008-2009), Technical University of Vienna Austria (2010) and Recently with Institute Chemical Technology of Prague Czech Republic (2012-now). His current job is as a full professor in the field of material engineering at the Department of Mechanical Engineering, Engineering Faculty, Udayana University, Jimbaran, Bali, Indonesia. His research interests include biomaterial, waste recycle, failure analyses, ceramic, metallurgy, composite, renewable energy, and environmental friendly manufacturing.

Prof. Nindhia is a member of JICA Alumni, ASEA-UNINET alumni, International Association of Computer Science and Information Technology (IACSIT), Asia-Pacific Chemical, Biological \& Environmental Engineering Society (APCBEES) and also one member of Association of Indonesian Nanotechnology. Prof Nindhia received the best researcher award in 1997 and in 2013 from Udayana University the place where he is working and again in 2012 received both Best Lecturer Award from Engineering Faculty of Udayana University. In the same years 2012, the research center of Udayana university awarded Prof Nindhia as the best senior researcher. In 2013, Prof. Nindhia was awarded as 15 best performance Indonesian lecturers from Ministry of Education and Culture the Republic of Indonesia. Prof Nindhia received the best paper award during International Conference on Environmental Engineering and Development (ICEED) 2014 in Sydney, Australia.

I. Wayan Surata was born in Nusa Penida, Bali, Indonesia on July 5, 1958 $\mathrm{He}$ received the doctor degree in the field of ergonomic from Udayana University in 2011. His research interest very much related in process of manufacture. His current job is a researcher and lecturer at the Department of Mechanical Engineering, Engineering Faculty, Udayana University, Jimbaran, Bali, Indonesia.

I. Dewa Gede Putra Swastika was born in Bali, Indonesia on November 22, 1955. His current job is a researcher and lecturer at the Department of Mechanical Engineering, Engineering Faculty, Udayana University, Jimbaran, Bali, Indonesia

I. Made Wahyudi was an undergraduate student at Mechanical Engineering, Udayana University, Jimbaran, Bali, Indonesia and graduated during 2014. 